\title{
An infant with congenital nephrogenic diabetes insipidus presenting with hypercalcemia and hyperphosphatemia
}

\section{Katsuo Tao', Midori Awazu², Misa Honda², Hironori Shibata², Takayasu Mori3, Shinichi Uchida ${ }^{3}$, Tomonobu Hasegawa² and Tomohiro Ishii}

'Department of Pediatrics, Fukui Aiiku Hospital, Fukui, Japan, 2Department of Pediatrics, Keio University School of Medicine, shinjyuku, Tokyo, Japan, and ${ }^{3}$ Department of Nephrology, Tokyo Medical and Dental University, Fukui, Japan
Correspondence

should be addressed

to K Tao

Email

katsuo1203@yahoo.co.jp

\section{Summary}

We report a male infant with congenital nephrogenic diabetes insipidus (NDI) who presented with hypercalcemia and hyperphosphatemia since birth. Serum sodium started to increase at 39 days. Although there was no polyuria, urine osmolality was $71 \mathrm{mOsm} / \mathrm{kg}$, when serum osmolality was $296 \mathrm{mOsm} / \mathrm{kg}$ with plasma arginine vasopressin $22.5 \mathrm{pg} / \mathrm{mL}$. He was thus diagnosed as NDI. An undetectable level of urine calcium and unsuppressed intact parathyroid hormone suggested hyperparathyroidism including calcium-sensing receptor mutations that could cause hypercalcemia-induced NDI. Polyuria became apparent after the initiation of i.v. infusion for the treatment of hypernatremia. Low calcium and low sodium formula with hypotonic fluid infusion did not correct hypernatremia, hypercalcemia, or hyperphosphatemia. Hydrochlorothiazide and subsequently added celecoxib effectively decreased urine output and corrected electrolytes abnormalities. Normal serum electrolytes were maintained after the discontinuation of low calcium formula. The genetic analysis revealed a large deletion of the arginine vasopressin receptor-2 (AVPR2) gene but no pathogenic variant in the calcium-sensing receptor (CASR) gene. Whether hypercalcemia and hyperphosphatemia were caused by dehydration alone or in combination with other mechanisms remains to be clarified.

\section{Learning points:}

- Congenital NDI can present with neonatal hypercalcemia and hyperphosphatemia.

- Hypercalcemia and hyperphosphatemia can be treated with low calcium and low sodium formula, hydration, hydrochlorothiazide, and celecoxib.

- Genetic testing is sometimes necessary in the differentiating diagnosis of hypercalcemia associated with NDI.

\section{Background}

Nephrogenic diabetes insipidus (NDI) is a disease characterized by inability to concentrate urine in response to arginine vasopressin (AVP) (1). Failure to conserve water results in polyuria, polydipsia, and hypernatremic dehydration. NDI can be congenital or acquired. Congenital NDI is inherited as an X-linked trait due to AVP receptor-2 (AVPR2) gene abnormality or autosomally due to aquaporin-2 (AQP2) gene abnormality. Acquired NDI is caused by hypercalcemia, hypokalemia, drugs such as lithium, kidney diseases, and others (1). While hypercalcemia causes NDI, there is no report of congenital NDI complicated with hypercalcemia. We describe an infant with congenital NDI who presented with hypercalcemia along with hyperphosphatemia. We 
initially suspected calcium and phosphate metabolism disorders but the genetic testing led to the diagnosis of congenital NDI.

\section{Case presentation}

A male infant was vaginally delivered at 33 weeks gestation with a birth weight of $1890 \mathrm{~g}$ and a height of $44.5 \mathrm{~cm}$. The pregnancy was the result of in vitro fertilization-embryo transfer. There was no polyhydramnios. Apgar score was 8 and 9 at 1 and $5 \mathrm{~min}$, respectively. He was the first child with unremarkable family history. Heart rate was 124 times per min, blood pressure was $54 / 24 \mathrm{mmHg}$, and respiratory rate was 60 per min. He had marked respiratory distress with nasal flaring, retractions, and grunting. The oxygen saturation was $89 \%$, and he was placed on the nasal continuous positive airway pressure after admission to neonatal intensive care unit. Laboratory findings are shown in Table 1 . At 4 days, the nasal continuous positive airway pressure was withdrawn. Hypercalcemia was noted since birth, and serum phosphate level increased to $7.8 \mathrm{mg} / \mathrm{dL}$ at 4 days (Fig. 1A). Blood urea nitrogen was $5 \mathrm{mg} / \mathrm{dL}$, and serum creatinine was $1.03 \mathrm{mg} / \mathrm{dL}$. He was well hydrated receiving $100 \mathrm{~mL} / \mathrm{kg} /$ day of breast milk through a nasogastric tube. As bloody stool was noted at 6 days, enteral feeding was stopped. Serum sodium level increased to $149 \mathrm{mEq} / \mathrm{L}$, and we increased the i.v. infusion. Enteral feeding was resumed at 7 days. Serum calcium increased to $13.5 \mathrm{mg} / \mathrm{dL}$ at 10 days but decreased to $11.0 \mathrm{mg} / \mathrm{dL}$ at 14 days with the increase in breast milk intake. Intravenous infusion was discontinued at 15 days. The levels of serum calcium and ionized calcium increased from 10.3 to $13.1 \mathrm{mg} / \mathrm{dL}$ and from 1.35 to 1.45 $\mathrm{mmol} / \mathrm{L}$, respectively. Urine calcium was undetectable. Serum sodium was also increased to $152 \mathrm{mEq} / \mathrm{L}$ at 39 days. Blood urea nitrogen was $10.2 \mathrm{mg} / \mathrm{dL}$, serum creatinine was $0.44 \mathrm{mg} / \mathrm{dL}$, and serum albumin was $4.5 \mathrm{~g} / \mathrm{dL}$.

When serum osmolality was $296 \mathrm{mOsm} / \mathrm{kg}$, urine osmolality was $71 \mathrm{mOsm} / \mathrm{kg}$, and plasma AVP was 22.5 $\mathrm{pg} / \mathrm{mL}$. He was thus diagnosed as NDI. Urinary AQP2 was undetected, and renal ultrasonography showed no abnormalities. Although his body weight increased with increased breast milk intake, i.v. infusion had to be restarted because hypernatremia did not improve. Polyuria became apparent after the restart of infusion, with urine volume exceeding $2500 \mathrm{~mL} / \mathrm{m}^{2}$ at 63 days (Fig. 1B). Endocrinological studies revealed serum levels of 1.25 $(\mathrm{OH})_{2}$ vitamin D: $87.8 \mathrm{pg} / \mathrm{mL}$ (normal range (NR): 20-70 $\mathrm{pg} / \mathrm{mL}$ ), $25(\mathrm{OH})$ vitamin D: $17 \mathrm{ng} / \mathrm{mL}$ (NR: $10-30 \mathrm{ng} / \mathrm{mL}$ ), parathyroid hormone-related protein below $1.0 \mathrm{pmol} / \mathrm{L}$,
Table 1 Laboratory findings on admission.

\begin{tabular}{|c|c|}
\hline Parameters & Values \\
\hline \multicolumn{2}{|l|}{ Blood count } \\
\hline $\mathrm{WBC} / \mu \mathrm{L}$ & $1.3 \times 10^{4}$ \\
\hline Hemoglobin, g/dL & 20.8 \\
\hline Hematocrit, $\%$ & 59.2 \\
\hline Platelet/ $\mu \mathrm{L}$ & $36.3 \times 10^{3}$ \\
\hline \multicolumn{2}{|l|}{ Chemistry } \\
\hline Albumin, g/dL & 4.1 \\
\hline$A L P, U / L$ & 593 \\
\hline $\mathrm{BUN}, \mathrm{mg} / \mathrm{dL}$ & 5.6 \\
\hline Creatinine, $\mathrm{mg} / \mathrm{dL}$ & 0.58 \\
\hline $\mathrm{Na}, \mathrm{mEq} / \mathrm{L}$ & 140 \\
\hline $\mathrm{K}, \mathrm{mEq} / \mathrm{L}$ & 6.1 \\
\hline $\mathrm{Cl}, \mathrm{mEq} / \mathrm{L}$ & 107 \\
\hline $\mathrm{Ca}, \mathrm{mg} / \mathrm{dL}$ & 10.8 \\
\hline $\mathrm{P}, \mathrm{mg} / \mathrm{dL}$ & 7.0 \\
\hline $\mathrm{Ca}^{2+}, \mathrm{mmol} / \mathrm{L}$ & 1.47 \\
\hline $\mathrm{Mg} *, \mathrm{mg} / \mathrm{dL}$ & 3.1 \\
\hline $\mathrm{CRP}, \mathrm{mg} / \mathrm{dL}$ & 0 \\
\hline \multicolumn{2}{|l|}{ Venous blood gas } \\
\hline $\mathrm{PH}$ & 7.215 \\
\hline $\mathrm{PCO}_{2}, \mathrm{mmHg}$ & 60.5 \\
\hline Base excess, $\mathrm{mmHg}$ & -5.5 \\
\hline $\mathrm{HCO}_{3}^{-}, \mathrm{mmol} / \mathrm{L}$ & 23.9 \\
\hline \multicolumn{2}{|l|}{ Urinalysis } \\
\hline Protein & - \\
\hline Blood & - \\
\hline Sugar & - \\
\hline Specific gravity & 1.002 \\
\hline \multicolumn{2}{|l|}{ Urine electrolytes } \\
\hline $\mathrm{Na}, \mathrm{mEq} / \mathrm{L}$ & 28 \\
\hline $\mathrm{K}, \mathrm{mEq} / \mathrm{L}$ & 12 \\
\hline $\mathrm{Cl}, \mathrm{mEq} / \mathrm{L}$ & 28 \\
\hline Creatinine, $\mathrm{mg} / \mathrm{dL}$ & 14.59 \\
\hline Cat, mg/dL & 0 \\
\hline
\end{tabular}

*On day 52; ${ }^{\dagger}$ On day 39.

ALP, alkaline phosphatase; BUN, blood urea nitrogen; CRP, C-reactive protein; WBC, white blood cells.

and angiotensin converting enzyme: 17.5 U/L (NR: 7-25 $\mathrm{U} / \mathrm{L})$ at 68 days. Serum intact parathyroid hormone (PTH) level was $22 \mathrm{pg} / \mathrm{mL}$ (NR: 10-65 pg/mL), and fibroblast growth factor 23 level was $38 \mathrm{pg} / \mathrm{mL}$ (NR: 19.9-52.9 pg/mL), and urine calcium was undetectable when the serum ionized calcium level was $1.31 \mathrm{mmol} / \mathrm{L}$ at 74 days. These results suggested that calcium and phosphate metabolism disorders specifically as neonatal hyperparathyroidism or familial hypocalciuric hypercalcemia (FHH).

\section{Treatment}

To correct electrolytes abnormalities, low phosphate formula, which had been started at 72 days, was changed to the mixture of vitamin D-free low calcium formula and low sodium formula at 75 days. The 
(n)
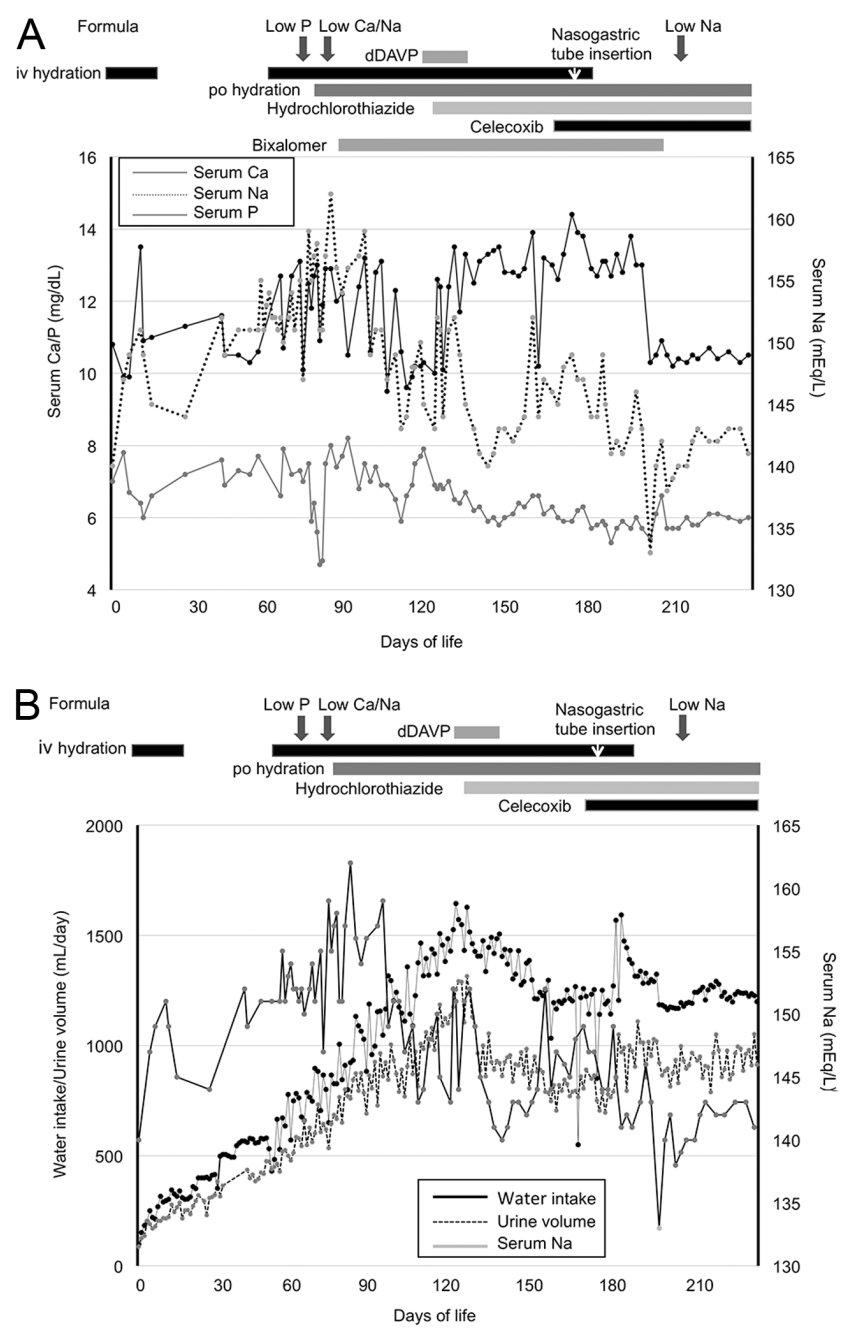

Figure 1

Clinical and laboratory course. (A) Serum calcium/phosphate and sodium hypercalcemia and hyperphosphatemia were noted since birth. Serum sodium started to increase on day 39 , which changed in correlation with serum calcium and phosphate. Low calcium and low sodium formula did not correct electrolytes abnormalities. Bixalomer decreased serum phosphate, and subsequently started hydrochlorothiazide and celecoxib, corrected hyperphosphatemia, hypernatremia, and hypercalcemia, in this order. (B) Water intake/urine and serum sodium polyuria became apparent after the initiation of i.v. infusion. Urine volume increased as infusion volume was increased. Hydrochlorothiazide and celecoxib decreased urine volume. dDVAP, desmopressin acetate hydrate; Vit. D, vitamin D.

mixed formula, however, did not correct electrolytes abnormalities, and bixalomer $20 \mathrm{mg} / \mathrm{kg} /$ day was initiated at 82 days. With increasing doses of bixalomer, serum phosphate gradually decreased but hypernatremia and hypercalcemia persisted. Nephrogenic cyclic AMP (cAMP) was $161.95 \mathrm{nmol} / \mathrm{dL}$ (NR: $0.29-2.81 \mathrm{nmol} / \mathrm{dL}$ ) at 92 days. Parathyroid gland was not visible in ultrasonography. Follow-up endocrinological studies revealed serum levels of $1.25(\mathrm{OH})_{2}$ vitamin D $81 \mathrm{pg} / \mathrm{mL}$ and $25(\mathrm{OH})$ vitamin D
$23 \mathrm{ng} / \mathrm{mL}$ on day 105. Since electrolytes abnormalities were not corrected with further increase of free water by i.v. infusion, nasal desmopressin acetate hydrate was tried at 115 days without any success. At that time, blood urea nitrogen was $7.4 \mathrm{mg} / \mathrm{dL}$, serum creatinine was $0.3 \mathrm{mg} / \mathrm{dL}$, and serum albumin was $3.7 \mathrm{~g} / \mathrm{dL}$. Hydrochlorothiazide $1 \mathrm{mg} / \mathrm{kg} /$ day was started at 124 days, which decreased urine volume. In an effort to discontinue the i.v. infusion, hydrochlorothiazide was increased to $2 \mathrm{mg} / \mathrm{kg} /$ day at 129 days. Celecoxib $7 \mathrm{mg} / \mathrm{kg} /$ day was added at 160 days, and urine volume decreased, in association with an increase in urine osmolality up to $88 \mathrm{mOsm} / \mathrm{kg}$ and normalization of serum sodium levels. Enteral fluid supplementation through a nasogastric tube, however, was necessary to discontinue infusion, in addition to increasing celecoxib to $12 \mathrm{mg} / \mathrm{kg} /$ day. As hypercalcemia improved at 192 days, bixalomer was discontinued at 207 days with no recurrence of hyperphosphatemia, and the mixed formula was changed to low sodium formula only at 209 days.

\section{Investigation}

Genetic analysis using next-generation sequencing with a custom panel revealed a large deletion of the AVPR2 gene (NC_000023.10:g.(153167925_153168405)del) (2). Array comparative genomic hybridization (CGH) using 400K probe did not detect a deletion. There was no pathogenic variant in $A Q P 2$, and CASR.

\section{Outcome and follow-up}

After discharge, follow-up endocrinological studies revealed serum levels of $1.25(\mathrm{OH})_{2}$ vitamin D $55.2 \mathrm{pg} / \mathrm{mL}$ and intact PTH $26 \mathrm{pg} / \mathrm{mL}$ when the level of serum calcium and phosphate $10.1 \mathrm{mg} / \mathrm{dL}$ and $4.0 \mathrm{mg} / \mathrm{dL}$, respectively. Nasogastric hydration was discontinued when he was 1 year and 6 months. Now he is 2 years and 4 months old with normal growth and development.

\section{Discussion}

We report an infant with congenital NDI presenting with hypercalcemia and hyperphosphatemia. This association has not previously been reported. In our patient, hypercalcemia and hyperphosphatemia had been present since birth before the appearance of hypernatremia. We, therefore, speculated calcium and phosphate metabolism disorders specifically as neonatal primary hyperparathyroidism (PHPT) or FHH. Other causes of 
hypercalcemia such as hypervitaminosis $\mathrm{D}$ and $\mathrm{A}$, adrenal insufficiency, and malignancy were unlikely or ruled out.

Hypercalcemia along with an undetectable urine calcium level made us to suspect FHH or neonatal PHPT (3). These two diseases are caused by pathogenic variant of CASR. In sensing the elevated serum ionized calcium level, CASR suppresses PTH secretion, $1,25(\mathrm{OH})_{2}$ vitamin D synthesis, renal tubular calcium reabsorption, and intestinal calcium absorption (4). Due to the inactivating CASR mutations, patients with FHH or neonatal PHPT fail to suppress PTH secretion and urinary calcium secretion despite the presence of hypercalcemia (3). His unsuppressed PTH level in the presence of hypercalcemia was considered to be consistent with hyperparathyroidism. A high level of nephrogenic cAMP, $1,25(\mathrm{OH})_{2}$ vitamin D, and a normal level of fibroblast growth factor 23 were also compatible with FHH or neonatal PHPT.

During treatment of the electrolyte abnormalities, a diagnosis of NDI was made. We used the mixture of low calcium and low sodium formula to correct both hypercalcemia and hypernatremia. For hyperphosphatemia, we started bixalomer, and the serum phosphate decreased with increasing dose. Hypercalcemia and hypernatremia, however, persisted, and we restarted i.v. infusion. Polyuria became apparent thereafter.

We initially suspected that NDI was secondary to hypercalcemia (5). The treatment of NDI secondary to hypercalcemia is the correction of the latter. Of note, despite hypercalcemia, patients with inactivating mutation of CASR have been reported to have normal concentrating ability (6). Furthermore, with the combination therapy of hydrochlorothiazide and celecoxib, the serum calcium decreased. This clinical course suggested that NDI was not secondary to hypercalcemia, and there was no pathogenic variant in CASR. Hypercalcemia and hyperphosphatemia in our patient were, therefore, most likely caused by dehydration due to congenital NDI.

Although uncommon, hypercalcemia and hyperphosphatemia could occur during dehydration (7). Thus Fernandes et al reported a patient who presented with hypercalcemia, hypophosphatemia, and severe hypovolemia. In that patient, other causes of hypercalcemia such as vitamin A and D intoxication, sarcoidosis, and CASR mutations were ruled out, and rehydration corrected hypercalcemia (7). Of note, hyperphosphatemia coexisted with hypercalcemia in our patient. The differential diagnosis of this condition is vitamin D intoxication. In fact, his $1,25(\mathrm{OH})_{2}$ vitamin D level was elevated. Vitamin D increases intestinal absorption of phosphate and phosphate reabsorption at proximal tubules (8). The causes of high $1,25(\mathrm{OH})_{2}$ vitamin D level include granulomatous diseases such as sarcoidosis and hyperparathyroidism (8). His angiotensin converting enzyme level was normal, however, and there were no signs of granulomatous disease. The level of $1,25(\mathrm{OH})_{2}$ vitamin D and PTH normalized after the electrolytes abnormalities were corrected. Hypocalciuria, which had been observed since birth can be caused by FHH, vitamin D deficiency, Gitelman syndrome, and CASR autoantibodies (9). None of these were present, and the cause of hypocalciuria remained unclear.

The translocation or trafficking of AQP2 is dependent on cAMP produced by AVP. AQP2 expression in the kidneys and urinary AQP2 excretion were significantly reduced in several rat models of NDI (5). The changes in the urinary excretion of AQP2, therefore, can be used as an index of the action of AVP in the kidney (10). Urinary AQP2 excretion was decreased in patients with congenital NDI due to the AVPR2 gene deletion and the AQP2 gene deletion as well as those with acquired NDI due to hypercalcemia, hypokalemia, and others (10).

We report an infant with congenital NDI due to a large deletion of the AVPR2 gene, who presented with hypercalcemia and hyperphosphatemia. He was initially suspected with $\mathrm{FHH}$, which was ruled out by genetic analysis and subsequent clinical course. Hypercalcemia and hyperphosphatemia improved after the treatment of NDI with hydration, hydrochlorothiazide, and celecoxib. Whether they were caused by dehydration alone or in combination with other mechanisms remains unknown.

\section{Declaration of interest}

The authors declare that there is no conflict of interest that could be perceived as prejudicing the impartiality of the research reported.

\section{Funding}

This research did not receive any specific grant from any funding agency in the public, commercial or not-for-profit sector.

\section{Patient consent}

A full written consent has been obtained from the parent of the patient.

\section{Author contribution statement}

Tao was a patient's physician involved in the clinical care of the patient and collected the data. Awazu and Ishii supervised the management of the patient. Tao and Awazu prepared the manuscript and Honda, Shibata, Mori, Uchida, Hasegawa, and Ishii were involved in genetic analysis. 


\section{Acknowledgements}

The authors thank Dr Takeshi Sato and Dr Satoshi Narumi, Department of Pediatrics, Keio University School of Medicine for their help in genetic analysis.

\section{References}

1 Wesche D, Deen PM \& Knoers NV. Congenital nephrogenic diabetes insipidus: the current state of affairs. Pediatric Nephrology 201227 2183-2204. (https://doi.org/10.1007/s00467-012-2118-8)

2 Mori T, Hosomichi K, Chiga M, Mandai S, Nakaoka H, Sohara E, Okado T, Rai T, Sasaki S, Inoue I, et al. Comprehensive genetic testing approach for major inherited kidney diseases, using next-generation sequencing with a custom panel. Clinical Experimental Nephrology 201721 63-75. (https://doi.org/10.1007/s10157-016-1252-1)

3 Lee JY \& Shoback DM. Familial hypocalciuric hypercalcemia and related disorders. Best Practice and Research: Clinical Endocrinology and Metabolism 201832 609-619. (https://doi.org/10.1016/j. beem.2018.05.004)

4 Riccardi D \& Brown EM. Physiology and pathophysiology of the calcium-sensing receptor in the kidney. American Journal of Physiology: Renal Physiology 2010298 F485-F499. (https://doi. org/10.1152/ajprenal.00608.2009)
5 Khanna A. Acquired nephrogenic diabetes insipidus. Seminars in Nephrology 200626 244-248. (https://doi.org/10.1016/j. semnephrol.2006.03.004)

6 Sands JM , Naruse M, Baum M, Jo I, Hebert SC, Brown EM \& Harris HW. Apical extracellular calcium/polyvalent cation-sensing receptor regulates vasopressin-elicited water permeability in rat kidney inner medullary collecting duct. Journal of Clinical Investigation 199799 1399-1405. (https://doi.org/10.1172/ JCI119299)

7 Fernandes LG, Ferreira NR, Cardiga R \& Póvoa P. Severe hypercalcaemia and colon ischaemia: dehydration as an unusual cause? BMJ Case Reports 20152015 bcr2014208809. (https://doi. org/10.1136/bcr-2014-208809)

8 Tebben PJ, Singh RJ \& Rajiv Kumar R. Vitamin D-mediated hypercalcemia: mechanisms, diagnosis, and treatment. Endocrine Reviews 201637 521-547. (https://doi.org/10.1210/er.2016-1070)

9 Bianchetti MG, Edefonti A \& Bettinelli A. The biochemical diagnosis of Gitelman disease and the definition of 'hypocalciuria'. Pediatric Nephrology 200318 409-411. (https://doi.org/10.1007/s00467-0031084-6)

10 Kanno K, Sasaki S, Hirata Y, Ishikawa S, Fushimi K, Nakanishi S, Bichet DG \& Marumo F. Urinary excretion of aquaporin-2 in patients with diabetes insipidus.New England Journal of Medicine 1995332 1540-1545. (https://doi.org/10.1056/ NEJM199506083322303)

Received in final form 13 November 2020 Accepted 23 March 2021 